\title{
Granule for Rectal Suspension Dosage Form
}

National Cancer Institute

\section{Source}

National Cancer Institute. Granule for Rectal Suspension Dosage Form. NCI Thesaurus.

Code C149551.

Solid preparation consisting of aggregated particles that may include excipients to facilitate wetting and dispersion, intended to be dispersed in the specified liquid to obtain a rectal suspension, which is usually prepared just before administration to the patient. 